\title{
Analisis Pengaruh Perceived Quality Terhadap Brand Trust, Brand Attachment, Dan Brand Commitment (Studi pada pengguna smartphone Samsung)
}

\author{
Reno Vancasavio, Farida Indriani ${ }^{1}$ \\ ${ }^{1}$ Jurusan Manajemen Fakultas Ekonomika dan Bisnis Universitas Diponegoro \\ Jl. Prof. Soedharto SH Tembalang, Semarang 50239. Email: fa_oke@yahoo.com/ \\ reno.vancasavio@gmail.com
}

\begin{abstract}
This study aims to analyze perceived quality towards brand trust, brand attachment, and brand commitment to smartphone users especially Samsung. The reasons why using perceived quality as a variable because it has direct role to the users that takes a parts of having Samsung smartphone.

Non-probability technique was used for sampling and the population are Samsung smartphone users that has 18-24 years old range. Data were collected from 150 respondents which were selected using criteria of judgments that should has Samsung as their smartphone for minimal one year and students at Semarang. Test method is a Maximum likelihood analysis with AMOS program version 21.0.

The results showed that perceived quality variable directly giving positive influence towards brand trust, brand attachment, and brand commitment. Since three of the variables that have been influenced by perceived quality, one of the most influenced by perceived quality is brand trust.
\end{abstract}

Keywords: Perceived Quality, Brand Trust, Brand Attachment, and Brand Commitment

\section{Pendahuluan}

Perkembangan teknologi yang semakin maju di dunia bahkan di Indonesia, membawa perubahan yang signifikan di berbagai bidang, terutama di bidang teknologi komunikasi. Adanya perkembangan teknologi menyebabkan terjadinya alih fungsi dari telepon genggam, yang awalnya hanya digunakan sebagai kemudahan untuk telepon dan mengirim pesan singkat berubah menjadi telepon genggam pintar atau yang kita kenal dengan smartphone. Perkembangan smartphone yang sudah menjadi tren di dalam kehidupan sehari-hari juga tidak lepas dari peran internet yang dapat membuat smartphone menjadi sebuah kewajiban. Peranan internet yang mempunyai peran utama dalam penggunaan smartphone, memberikan berbagai kemudahan seperti telepon dengan gratis dari berbagai negara yang hanya menggunakan layanan internet, kemudahan dalam mengirim pesan baik pesan gambar, lagu, bahkan video, kemudahan transaksi yang juga bisa dilakukan melalui smartphone, dan berbagai kegunaan lainnya yang tentunya membuat smartphone wajib untuk dimiliki.

Berbagai fasilitas yang ditawarkan oleh smartphone membuat terjadinya kenaikan yang signifikan di dalam penggunaannya dari tahun ke tahun. Penggunaan smartphone yang meningkat ini membuktikan bahwa dengan kemudahan-kemudahan yang ditawarkan merupakan hal yang dinanti-nanti oleh para pengguna smartphone. Dengan banyaknya minat 
terhadap smartphone khususnya Samsung, hal ini menjadi sebuah tantangan baru bagi perusahaan pengembang telepon genggam khususnya Samsung, tentang bagaimana cara meningkatkan dan mempertahankan kesetiaan pelanggan terhadap suatu merek?. Pertanyaan ini menjadi suatu tantangan besar di kalangan profesional, perusahaan-perusahaan besar, juga menjadi hal yang diteliti terus menerus oleh peneliti.

Merek merupakan suatu topik yang sangat menarik di dalam penelitian, termasuk konsep dalam brand identity (Kapferer, 2008), brand image (Keller, 2013), dan terakhir adalah brand equity (Aaker, 2011). Brand identity yang kita kenal dengan identitas merek, melibatkan semua elemen dalam pembentukan dari adanya sebuah merek. Sebaliknya, brand image adalah sebuah konsep penerimaan. Kapferer (2008) menjelaskan bahwa brand image merupakan hasil dari interpretasi dari merek itu sendiri (simbol, komunikasi, nama). Konsep dari ekuitas merek (brand equity) adalah nilai tambah yang diterima oleh konsumen terhadap merek yang digunakan (Aaker, 1997). Konsep dari ekuitas merek ini memiliki lima konsep utama yaitu brand awareness, perceived quality, brand association, brand loyalty, dan asetaset lainnya. Dari kelima konsep utama dalam ekuitas merek, salah satu hal yang menarik untuk diteliti dalam upaya mempertahankan hubungan relasi dengan konsumen adalah mengetahui bagaimana peran dari perceived quality atau yang dikenal dengan persepsi kualitas.

Penelitian ini bertujuan untuk meneliti kaitan dari persepsi kualitas dengan tiga konsep yang menyangkut hubungan antara perusahaan dan konsumen, diantaranya: brand trust, brand attachment, dan brand commitment. Berdasarkan pada penelitian sebelumnya yang dilakukan oleh Louis (2010) yang menggunakan indikator brand personality sebagai variabel independen yang mempengaruhi brand trust, brand attachment, dan brand commitment menunjukkan bahwa ada sebuah pengaruh positif dari brand personality kepada variabel yang berkaitan yang akan diteliti. Hasil dari penelitian tersebut menyisakan suatu pertanyaan mengenai konsep dari brand personality, karena jika dilihat melalui konsep brand personality saja maka penelitian tersebut hanya mempertimbangkan peran konsumen secara emosional sebagai individu. Oleh karena itu, penelitian ini dilakukan untuk menelaah peran konsumen yang dilihat sebagai pengguna sebuah merek melalui variabel perceived quality.

\section{Telaah Pustaka Dan Pengembangan Hipotesis}

\section{Perceived Quality}

Pengertian tentang persepsi kualitas menurut Aaker (1997) adalah persepsi pelanggan terhadap keseluruhan kualitas atau keunggulan suatu produk atau jasa layanan yang berkaitan dengan maksud yang diharapkan. Adanya persepsi dari konsumen, merupakan hal yang harus dipenuhi oleh perusahaan karena menyangkut tentang keunggulan suatu produk atau jasa layanan, keunggulan sebuah produk atau jasa layanan menggambarkan reputasi dari perusahaan terkait.

Lebih lanjut Aaker (1997) mengungkapkan bahwa persepsi kualitas meliputi segala sesuatu yang berkaitan dengan bagaimana suatu merek dipersepsikan sehingga dengan diketahuinya persepsi dengan kualitas yang dimiliki, maka badan usaha dapat menentukan langkah-langkah apa yang dapat diambil guna memperkuat persepsi pelanggannya terhadap merek yang dimiliki oleh badan usaha tersebut.

\section{Brand Trust}

Kepercayaan merek adalah kemampuan merek untuk dipercaya, yang bersumber pada keyakinan konsumen bahwa produk tersebut mampu memenuhi nilai yang dijanjikan dan 
intensi baik merek yang didasarkan pada keyakinan konsumen bahwa merek tersebut mampu mengutamakan kepentingan konsumen (Delgado, 2004).

Merek adalah sebuah nama, istilah, tanda, simbol, desain, atau kombinasi dari hal-hal tersebut yang dimaksudkan untuk mengidentifikasi barang atau jasa dari penjual atau kelompok penjual dan untuk membedakannya dari barang atau jasa milik pesaing. Menurut Kotler dan Keller (2009) kepercayaan adalah suatu pengetahuan yang dimiliki oleh semua konsumen dan kesimpulan yang dibuat konsumen tentang objek, atribut, dan manfaatnya. Objek dapat berupa produk, orang, dan manfaatnya.

\section{Brand Attachment}

Brand attachment adalah derajat kesetiaan dari konsumen terhadap merek yang terkait, selain itu konsumen juga tidak akan terpengaruh apabila merek yang terkait mengalami kegagalan atau terdapat berita buruk, bahkan konsumen juga bisa menjadi adiktif atau ketergantungan terhadap merek tersebut (Keller, 2013). Jika konsumen tidak menggunakan produk dengan merek yang terkait maka konsumen tidak akan menggunakan produk yang serupa.

Teori attachment yang dikemukakan oleh Mikulincer dan Shaver (2007), menyatakan bahwa brand attachment adalah ikatan emosional antara konsumen dengan merek dan merupakan tujuan utama untuk menuju manajemen merek yang sukses, ikatan tersebut ditunjukkan dengan jaringan memori yang kaya dan dapat diakses atau merepresentasikan mental yang melibatkan pikiran dan perasaan tentang merek dan hubungan merek untuk diri.

\section{Brand Commitment}

Komitmen didefinisikan sebagai sebuah keinginan untuk menjaga hubungan yang dihargai dalam waktu lama (Moorman, 1992). Selain itu komitmen juga mendasari dari sebuah proses keberlanjutan untuk menjaga nilai dan hubungan penting yang sudah dibentuk melalui kepercayaan. Dalam bidang pemasaran, konsep dari komitmen sudah dipertimbangkan di berbagai area, termasuk pada perilaku konsumen, yang mana sudah terbukti dari berbagai definisi yang sudah ada.

Berdasarkan Morgan dan Hunt (1994) bahwa terdapat hubungan komitmen ketika konsumen percaya bahwa hubungan (merek) yang sekarang cukup penting daripada dengan yang lain, karena hubungan dengan merek yang sekarang berhak mendapatkan komitmen dari hasil usaha yang akan tetap dijaga

\section{Pengaruh Perceived Quality terhadap Brand Trust}

Morgan dan Hunt (1994) menemukan fenomena bahwa kepercayaan berpengaruh positif terhadap tingkat nilai yang sama dan memberikan informasi yang tepat waktu agar dapat menyelesaikan masalah perselisihan dan meluruskan persepsi dan juga harapan. Reputasi yang mana mengidentifikasi bahwa pengaruh kepercayaan terhadap perusahaan, mungkin dapat mudah timbul apabila digabungkan dengan persepsi kualitas dari Gronross (1990) yang mana kepercayaan konsumen terhadap perusahaan akan meningkat apabila terdapat kualitas yang baik di tingkat perusahaan yang terkait.

Oleh karena itu, semakin tinggi kualitas yang ditawarkan, semakin tinggi juga kepercayaan yang terbentuk antar konsumen dan perusahaan. Dalam penelitian terdahulu yang dilakukan oleh Gounoris (2003), menyatakan bahwa terdapat pengaruh positif antara kualitas yang diterima oleh konsumen dengan kepercayaan merek.

H1: Semakin tinggi perceived quality semakin tinggi brand trust. 


\section{Pengaruh Perceived Quality terhadap Brand Attachment}

Perusahaan dapat menciptakan respons yang positif, seperti loyalitas dan meningkatkan harga premium dengan cara menciptakan ikatan yang kuat antara konsumen dengan merek (Malar et al, 2011; Park et al, 2010). Adanya keterikatan yang kuat antara konsumen dengan perusahaan, membuat perusahaan harus melakukan perbaikan kualitas dalam produk, seperti yang diteliti oleh Wijaya (2014) dan Dennis (2015), di mana terdapat pengaruh positif antara keterlibatan produk yang berkaitan dengan perbaikan kualitas yang diterima oleh konsumen terhadap keterikatan merek tersebut.

H2: Semakin tinggi perceived quality semakin tinggi brand attachment.

\section{Pengaruh Perceived Quality terhadap Brand Commitment}

Persepsi kualitas juga selalu dikaitkan dengan adanya komitmen dari konsumen terhadap merek yang terkait. Selain itu Shukla (2015) menjelaskan bahwa pentingnya dalam meningkatkan komitmen malalui kualitas yang ada. Dengan adanya kualitas maka akan terbentuk komitmen yang kuat dari pengguna dalam produk atau objek yang terkait. Dalam penelitian terdahulu yang dilakukan oleh Listani (2013) dijelaskan bahwa terdapat pengaruh positif dari kepuasan yang berdasarkan persepsi kualitas terhadap komitmen konsumen pada suatu merek atau brand commitment.

H3: Semakin tinggi perceived quality semakin tinggi brand commitment.

\section{Pengaruh Brand Trust terhadap Brand Attachment}

Dalam penelitian sebelumnya terdapat hipotesis yang menunjukkan adanya pengaruh positif antara brand trust dan brand attachment (Rudolf, 2006). Selain itu dalam upaya untuk membedakan kepercayaan dan ketertarikan Rudolf (2006) menitikberatkan pada integritas dan kebaikan suatu merek yang kaitannya dalam unsur variabel kepercayaan menyerupai bahkan juga mempengaruhi unsur variabel ketertarikan merek. Sebagai tambahan, bahwa hipotesis yang berkaitan antara kepercayaan dan ketertarikan, sesuai dengan penelitian terkait yang dilakukan oleh Louis (2010), yang berasumsi bahwa terdapat pengaruh positif antara kepercayaan dan merek.

H4: Semakin tinggi brand trust semakin tinggi brand attachment.

\section{Pengaruh Brand Attachment terhadap Brand Commitment}

Keberadaan hubungan antara keterikatan dan komitmen merupakan hal yang penting, tingkat keterikatan konsumen terhadap merek dapat menjadikan tolak ukur bagaimana konsumen dapat loyal kepada merek, meskipun merek yang digunakan oleh konsumen selalu dibandingkan dengan kompetitor lain yang mengusung berbagai kegunaan dan fungsi yang lebih memadai. Shi Wen-hua (2011) mengindikasikan bahwa terdapat hubungan positif dari keterikatan terhadap suatu merek dengan loyalitas merek. Sementara itu, hipotesis pengaruh dari adanya keterikatan merek terhadap komitmen merek berasal dari penelitian Louis (2010).

H5 : Semakin tinggi brand attachment semakin tinggi brand commitment.

\section{Pengaruh Brand Trust terhadap Brand Commitment}

Komitmen kepada merek terkait yang digunakan oleh konsumen, jika ada sesuatu yang merugikan konsumen, akan menjadi konsekuensi yang diterima oleh konsumen. Hipotesis yang mempengaruhi kepercayaan merek dan komitmen merek digagas oleh 
Delgado (2001). Signifikansi yang positif antara kepercayaan merek dan komitmen terhadap merek terlihat pada penelitian sebelumnya yang dilakukan oleh Chauduri dan Holbrook (2001) dan Louis (2010).

H6: Semakin tinggi brand trust semakin tinggi brand commitment.

\section{Metode Penelitian}

Variabel independen adalah variabel bebas yang mempengaruhi variabel dependen baik pengaruhnya positif maupun negatif (Ferdinand, 2006). Dalam penelitian ini yang menjadi variabel independen adalah perceived quality. Variabel dependen merupakan variabel terikat yang menjadi pusat perhatian peneliti, yang dipengaruhi oleh variabel independen (Ferdinand, 2006). Variabel dependen dalam penelitian ini yaitu brand trust, brand attachment dan brand commitment. Populasi dalam penelitian ini adalah pengguna smartphone dengan target usia 18 sampai 24 tahun yang berstatus mahasiswa. Sampel dalam penelitian ini sebanyak 150 responden yang merupakan pengguna smartphone Samsung yang berada di kota Semarang khususnya sedang berkuliah di Fakultas Ekonomika dan Bisnis Universitas Diponegoro dan sudah menggunakan Samsung dengan minimal penggunaan satu tahun. Teknik analisis yang digunakan dalam penelitian ini adalah Structural Equation Modeling (SEM) yang dioperasikan melalui program AMOS 21.

\section{Hasil Penelitian Dan Pembahasan}

\section{Deskripsi Sampel Penelitian}

Data distribusi karakteristik demografi responden yang menjadi objek penelitian mempunyai persebaran jenis kelamin antara laki-laki dan perempuan yang cukup merata. Jumlah dari jenis kelamin laki-laki adalah 77 orang, sedangkan jumlah kelamin perempuan sejumlah 73 orang. Jika dijadikan dalam persentase maka dapat diperoleh laki-laki sebesar $51 \%$ sedangkan perempuan sebesar $49 \%$. Umur yang menjadi objek penelitian tersebar cukup merata diantaranya umur 19 tahun sebanyak 18 orang, umur 20 tahun sebanyak 37 orang, umur 21 tahun sebanyak 42 orang, umur 22 tahun sebanyak 33 orang, dan yang terakhir adalah umur 23 tahun sebanyak 20 orang.

Selain itu berdasarkan lama penggunaan smartphone dari responden maka dibagi menjadi dua kategori, yaitu lama penggunaan selama setahun dan penggunaan lebih dari satu tahun (>1 tahun). Responden yang menggunakan smartphone Samsung selama satu tahun sebesar $46 \%$, sedangkan responden yang menggunakan smartphone Samsung lebih dari satu tahun sebesar $54 \%$. 


\section{Pembahasan Hasil Penelitian}

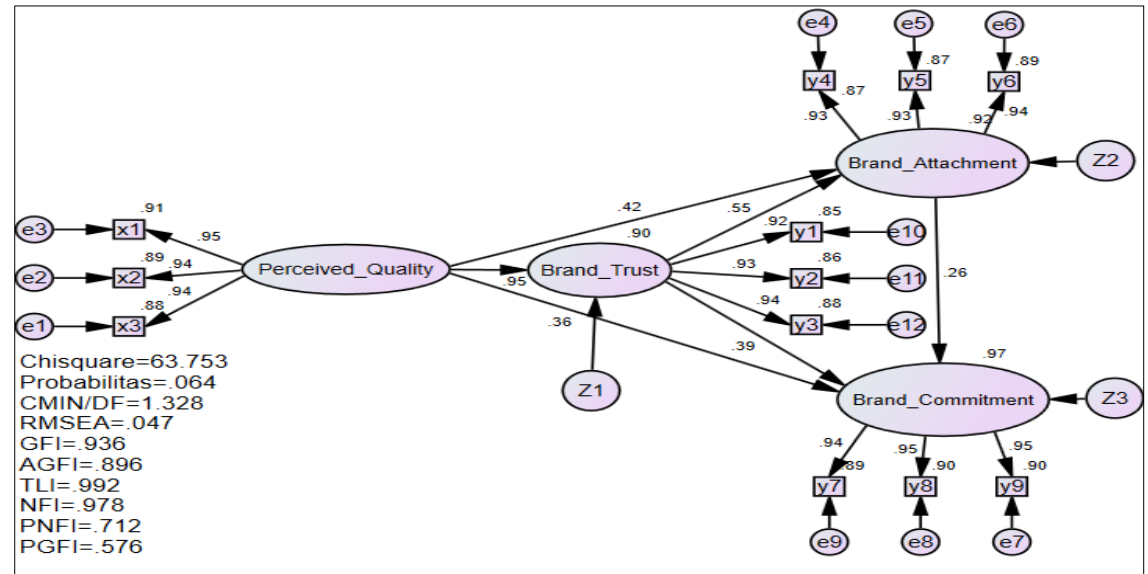

Gambar 1

Hasil Full Model Structural

Sumber: Data primer yang diolah (2016)

Hasil dari pengujian CFA (Confirmatory Factor Analysis) pada full model structural seperti yang ditunjukkan pada gambar 2 menunjukkan bahwa sebagian besar indeks berada pada kondisi fit yang berarti dapat dikatakan bahwa model dapat diterima. Selain itu sebagai pengujian lain bahwa model dapat diterima adalah dengan adanya penilaian bahwa semua indikator memberikan nilai loading factor $>0,50$ jadi sudah memenuhi convergent validity (Ghozali, 2011).

Tabel 1

Hasil Pengujian Kelayakan Model SEM

\begin{tabular}{|l|c|c|l|}
\hline \multicolumn{1}{|c|}{ Goodness-of-fit Idex } & $\begin{array}{c}\text { Cut Off } \\
\text { Value }\end{array}$ & $\begin{array}{c}\text { Hasil } \\
\text { Model }\end{array}$ & \multicolumn{1}{|c|}{ Keterangan } \\
\hline $\mathrm{X}^{2}$ Chi-Square & & 63,753 & Diharapkan nilai kecil \\
\hline $\mathrm{X}^{2}$ Significance Probability & $\geq 0,05$ & 0,064 & Fit \\
\hline RMSEA & $\leq 0,08$ & 0,047 & Fit \\
\hline GFI & $\geq 0,90$ & 0,936 & Fit \\
\hline AGFI & $\geq 0,90$ & 0,896 & Fit \\
\hline Relative $X^{2}$ (CMIN/DF) & $\leq 2,00$ & 1,328 & Fit \\
\hline TLI & $\geq 0,95$ & 0,992 & Fit \\
\hline CFI & $\geq 0,95$ & 0,997 & Fit \\
\hline NFI & $>0,90$ & 0,986 & Fit \\
\hline
\end{tabular}

Sumber: Data primer yang diolah (2016)

Berdasarkan pada analisis yang dilakukan diperoleh bahwa nilai chi-square 63,753 pada tingkat $\mathrm{df}=48$, kemudian nilai probabilitas atau probability level sebesar 0,064. Nilai RMSEA sebesar 0,047 dan dan semua kriteria goodness of fit $>0,90$. Dari hasil tersebut menggambarkan bahwa model penelitian adalah fit. Pengujian asumsi SEM yaitu sebagai berikut :

1. Evaluasi normalitas data terdiri dari normalitas univariate dan normalitas multivariate. Untuk mengetahui normalitas data dilakukan dengan menggunakan critical ratio skewness value dengan nilai $\pm 2,58$ pada tingkat signifikansi 0,01 (Ghozali, 2011). Dari hasil 
analisis data terdistribusi normal secara univariate. Kemudian secara multivariate data sudah terdistribusi normal, sehingga dapat disimpulkan bahwa data normal secara univariate dan multivariate dan dapat diterima.

2. Evaluasi atas outliers. Outlier adalah kondisi dari suatu data yang memiliki karakteristik unik yang terlihat berbeda jauh dari data lainnya dan muncul dalam bentuk nilai ekstrem (Ghozali, 2011). Untuk mengetahui data outlier dilakukan dengan melihat nilai mahalanobis distance dan chi-square tabel sesuai dengan indikator yang digunakan dalam penelitian. Perhitungan nilai mahalanobis distance dengan jumlah indikator dan tingkat signifikansi 0,01 maka diperoleh hasil $(12 ; 0,01)=32,90949$ yang merupakan batas maksimal outlier. Dari hasil penelitian data tertinggi pada mahalanobis distance sebesar 23,185 yang masih jauh dibawah batas maksimal data outlier, sehingga dapat disimpulkan bahwa data tidak ada outlier.

3. Evaluasi multikolinearitas dan singularitas dilakukan dengan melihat nilai determinan matriks kovarian. Nilai determinan yang sangat kecil menunjukkan indikasi terdapatnya masalah multikolinieritas atau singularitas, sehingga data itu tidak dapat digunakan untuk penelitian (Ghozali 2011). Berdasarkan hasil analisis memberikan nilai determinant of sample covariance matrix $=0,690$. Nilai tersebut jauh dari angka nol atau tidak mutlak pada angka 0 sehingga dapat disimpulkan bahwa tidak terdapat masalah multikolinieritas dan singularitas pada data yang dianalisis.

4. Evaluasi nilai residual dilakukan dengan critical ratio skewness value dengan nilai $\pm 2,58$ pada tingkat signifikansi 0,01 . Jika data yang dianalisis menghasilkan nilai yang jauh diatas $\pm 2,58$ maka terdapat indikasi adanya gangguan pada model. Hasil analisis data diperoleh nilai standardized residual covarians matrix pada rentang $\pm 2,58$ yang mengindikasikan tidak adanya gangguan pada model sehingga tidak diperlukan modifikasi model.

5. Evaluasi reliabilitas. Reliabilitas adalah ukuran konsistensi internal dari indikatorindikator sebuah variabel bentukan yang menunjukkan derajat sampai dimana masingmasing indikator itu mengindikasikan sebuah variabel bentukan yang umum. Terdapat dua cara yang dapat digunakan, yaitu construct reliability dan variance extracted. Cut-off value dari construct reliability adalah minimal 0,07 sedangkan cut-off value dari variance extracted minimal 0,05 (Ghozali, 2011). Dari hasil analisis data nilai reliability variabel perceived quality sebesar 0,961, variabel brand trust sebesar 0,954, variabel brand attachment sebesar 964, dan variabel brand commitment sebesar 0,950. Kemudian nilai variance extracted dari masing-masing variabel yaitu perceived quality sebesar 0,890 , variabel brand trust sebesar 0,874, variabel brand attachment sebesar 0,899, dan variabel brand commitment sebesar 0,864. Dari hasil analisis tersebut dapat disimpulkan bahwa nilai reliability dan variance extracted sesuai dengan kriteria.

\section{Pengujian Hipotesis}

Pengujian hipotesis dalam penelitian ini didasarkan pada nilai Critical Ratio $(C R)$ dari suatu hubungan kausalitas adalah sebagai berikut :

Tabel 2

Pengujian Hipotesis

\begin{tabular}{|c|c|c|c|c|c|}
\hline Variable & Estimate & S.E. & C.R. & $\mathbf{P}$ & Label \\
\hline \multirow{4}{*}{$\begin{array}{lll}\text { Brand_Trust } & <--- & \text { Perceived_Quality } \\
\text { Brand_Attachment } & <--- & \text { Brand_Trust } \\
\text { Brand_Attachment } & <--- & \text { Perceived_Quality } \\
\text { Brand_Commitment <--- } & \text { Brand_Trust }\end{array}$} & .924 & .051 & 18.242 & .000 & par_1 \\
\hline & .523 & .141 & 3.716 & .000 & par_2 \\
\hline & .386 & .136 & 2.845 & .004 & par_5 \\
\hline & .424 & .140 & 3.025 & .002 & par_3 \\
\hline
\end{tabular}




\begin{tabular}{|c|r|r|r|r|r|}
\hline Variable & Estimate & \multicolumn{1}{|c|}{ S.E. } & \multicolumn{1}{c|}{ C.R. } & P & Label \\
\hline Brand_Commitment <--- Brand_Attachment & .300 & .128 & 2.348 & .019 & par_4 \\
\cline { 2 - 7 } Brand_Commitment <--- Perceived_Quality & .385 & .120 & 3.217 & .001 & par_6 \\
\hline
\end{tabular}

Sumber: Data primer yang diolah (2016)

\section{H1: Semakin tinggi perceived quality maka semakin tinggi brand trust}

Pengaruh dari variabel perceived quality dipengaruhi oleh beberapa indikator yang menjadi pengukuran, antara lain adalah kualitas yang baik, fitur yang diberikan, dan ketahanan produk. Parameter estimasi dari pengaruh perceived quality terhadap brand trust adalah sebesar 0,924 dengan nilai signifikan pada $\mathrm{CR}=18,242$ yang berada di atas persyaratan $C R \geq 2,00$ dengan taraf signifikan 0,01 (1\%) sehingga hipotesis nol dapat ditolak dan hipotesis alternatif diterima. Dikarenakan hipotesis satu $(\mathrm{H} 1)$ diterima dan dapat disimpulkan bahwa perceived quality secara keseluruhan mempunyai pengaruh yang positif terhadap brand trust, dan dengan demikian hipotesis satu (H1) terbukti dan dapat diterima.

\section{H2: Semakin tinggi perceived quality maka semakin tinggi brand attachment}

Pengaruh dari variabel perceived quality dipengaruhi oleh beberapa indikator yang menjadi pengukuran, antara lain adalah kualitas yang baik, fitur yang diberikan, dan ketahanan produk. Parameter estimasi dari pengaruh perceived quality terhadap brand attachment adalah sebesar 0,386 dengan nilai signifikan pada $\mathrm{CR}=2,845$ yang berada di atas persyaratan $\mathrm{CR} \geq 2,00$ dengan nilai $\mathrm{p}$ sebesar 0,004 yang sudah memenuhi syarat $<0,05$ sehingga hipotesis nol dapat ditolak dan hipotesis alternatif diterima. Dikarenakan hipotesis dua (H2) diterima dan dapat disimpulkan bahwa perceived quality secara keseluruhan mempunyai pengaruh yang positif terhadap brand attachment, dan dengan demikian hipotesis dua $(\mathrm{H} 2)$ terbukti dan dapat diterima.

\section{H3: Semakin tinggi perceived quality maka semakin tinggi brand commitment}

Pengaruh dari variabel perceived quality dipengaruhi oleh beberapa indikator yang menjadi pengukuran, antara lain adalah kualitas yang baik, fitur yang diberikan, dan ketahanan produk. Parameter estimasi dari pengaruh perceived quality terhadap brand trust adalah sebesar 0,385 dengan nilai signifikan pada $\mathrm{CR}=3,217$ yang berada di atas persyaratan $\mathrm{CR} \geq 2,00$ dengan taraf signifikan 0,01 (1\%) sehingga hipotesis nol dapat ditolak dan hipotesis alternatif diterima. Dikarenakan hipotesis tiga $(\mathrm{H} 3)$ diterima dan dapat disimpulkan bahwa perceived quality secara keseluruhan mempunyai pengaruh yang positif terhadap brand commitment, dan dengan demikian hipotesis tiga (H3) terbukti dan dapat diterima.

\section{H4: Semakin tinggi brand trust maka semakin tinggi brand attachment}

Pengaruh dari variabel brand trust dipengaruhi oleh beberapa indikator yang menjadi pengukuran, antara lain adalah credibility, integrity, dan benevolence. Parameter estimasi dari pengaruh brand trust terhadap brand attachment adalah sebesar 0,523 dengan nilai signifikan pada $\mathrm{CR}=3,716$ yang berada di atas persyaratan $\mathrm{CR} \geq 2,00$ dengan taraf signifikan 0,01 (1\%) sehingga hipotesis nol dapat ditolak dan hipotesis alternatif diterima. Dikarenakan hipotesis empat (H4) diterima dan dapat disimpulkan bahwa brand trust secara keseluruhan mempunyai pengaruh yang positif terhadap brand attachment, dan dengan demikian hipotesis empat (H4) terbukti dan dapat diterima. 


\section{H5: Semakin tinggi brand trust maka semakin tinggi brand commitment}

Pengaruh dari variabel brand trust dipengaruhi oleh beberapa indikator yang menjadi pengukuran, antara lain adalah credibility, integrity, dan benevolence. Parameter estimasi dari pengaruh brand trust terhadap brand commitment sebesar 0,424 dengan nilai signifikan pada $\mathrm{CR}=3,025$ yang berada di atas persyaratan $\mathrm{CR} \geq 2,00$ dengan nilai $\mathrm{p}$ sebesar 0,002 yang sudah memenuhi syarat $<0,05$, sehingga hipotesis nol dapat ditolak dan hipotesis alternatif diterima. Dikarenakan hipotesis lima (H5) diterima dan dapat disimpulkan bahwa brand trust secara keseluruhan mempunyai pengaruh yang positif terhadap brand commitment, dan dengan demikian hipotesis lima (H5) terbukti dan dapat diterima.

\section{H6: Semakin tinggi brand attachment maka semakin tinggi brand commitment}

Pengaruh dari variabel brand attachment dipengaruhi oleh beberapa indikator yang menjadi pengukuran, antara lain adalah hubungan emosional dengan merek, keterikatan untuk terus menggunakan produk dan ketertarikan. Parameter estimasi dari pengaruh brand attachment terhadap brand commitment sebesar 0,300 dengan nilai signifikan pada $\mathrm{CR}=$ 2,348 yang berada di atas persyaratan $C R \geq 2,00$ dengan nilai $p$ sebesar 0,019 yang sudah memenuhi syarat $<0,05$, sehingga hipotesis nol dapat ditolak dan hipotesis alternatif diterima. Dikarenakan hipotesis enam (H6) diterima dan dapat disimpulkan bahwa brand attachment secara keseluruhan mempunyai pengaruh yang positif terhadap brand commitment, dan dengan demikian hipotesis enam (H6) terbukti dan dapat diterima.

\section{Kesimpulan} berikut:

Dari hasil penelitian yang telah dilakukan, maka dapat diambil kesimpulan sebagai

1. Dari hasil analisis yang telah dilakukan terlihat bahwa adanya pengaruh positif dari perceived quality terhadap brand trust pada pengguna smartphone Samsung. Adanya pengaruh yang positif tersebut menandakan bahwa semakin tinggi perceived quality maka akan semakin tinggi juga brand trust pengguna smartphone Samsung, begitu juga apabila semakin rendah perceived quality maka akan semakin rendah juga brand trust.

2. Dari hasil analisis yang telah dilakukan terlihat bahwa adanya pengaruh positif dari perceived quality terhadap brand attachment pada pengguna smartphone Samsung. Adanya pengaruh yang positif tersebut menandakan bahwa semakin tinggi perceived quality maka akan semakin tinggi juga brand attachment pengguna smartphone Samsung, begitu juga apabila semakin rendah perceived quality maka akan semakin rendah juga brand attachment.

3. Dari hasil analisis yang telah dilakukan terlihat bahwa adanya pengaruh positif dari perceived quality terhadap brand commitment pada pengguna smartphone Samsung. Adanya pengaruh yang positif tersebut menandakan bahwa semakin tinggi perceived quality maka akan semakin tinggi juga brand commitment pengguna smartphone Samsung, begitu juga apabila semakin rendah perceived quality maka akan semakin rendah juga brand commitment.

4. Dari hasil analisis yang telah dilakukan terlihat bahwa adanya pengaruh positif dari brand trust terhadap brand attachment pada pengguna smartphone Samsung. Adanya pengaruh yang positif tersebut menandakan bahwa semakin tinggi brand trust maka akan semakin tinggi juga brand attachment pengguna smartphone Samsung, begitu juga apabila semakin rendah brand trust maka akan semakin rendah juga brand attachment.

5. Dari hasil analisis yang telah dilakukan terlihat bahwa adanya pengaruh positif dari brand trust terhadap brand commitment pada pengguna smartphone Samsung. Adanya 
pengaruh yang positif tersebut menandakan bahwa semakin tinggi brand trust maka akan semakin tinggi juga brand attachment pengguna smartphone Samsung, begitu juga apabila semakin rendah brand trust maka akan semakin rendah juga brand attachment.

6. Dari hasil analisis yang telah dilakukan terlihat bahwa adanya pengaruh positif dari brand attachment terhadap brand commitment pada pengguna smartphone jenis Samsung khususnya di Kota Semarang. Adanya pengaruh yang positif tersebut menandakan bahwa semakin tinggi brand attachment maka akan semakin tinggi juga brand commitment pengguna smartphone Samsung, begitu juga apabila semakin rendah brand attachment maka akan semakin rendah juga brand commitment.

\section{Keterbatasan Penelitian}

Penelitian ini dilakukan untuk mengetahui apakah kualitas yang diterima oleh pengguna smartphone (perceived quality) berpengaruh terhadap trust, attachment, dan commitment. Studi di dalam penelitian ini masih menggunakan populasi dan sampel yang hanya terbatas. Populasi yang digunakan adalah pengguna smartphone dengan target usia 18 sampai 24 tahun yang berstatus mahasiswa., sedangkan sampel dari penelitian ini adalah mahasiswa yang menggunakan smartphone Samsung yang berada di Fakultas Ekonomika dan Bisnis Universitas Diponegoro Semarang. Seperti yang diketahui bahwa penggunaan smartphone saat ini adalah hal yang wajib untuk dimiliki dari setiap kalangan baik mahasiswa maupun umum, sehingga berdampak pada generalisasi studi yang bersifat terbatas, sehingga tidak memungkinkan untuk memperluas cakupan dalam memperoleh hasil penelitian yang lebih valid. Indikator yang mampu menjelaskan variabel ini masih memungkinkan untuk ditambah dalam memperoleh hasil penelitian yang lebih baik.

Saran untuk penelitian yang mendatang adalah dari hasil analisis perhitungan yang telah dilakukan menunjukkan bahwa indikator-indikator yang ada dalam model pengembangan SEM ini masih memungkinkan untuk dapat dikembangkan dengan lebih bervariasi agar memperoleh hasil penelitian yang lebih baik. Selain itu faktor-faktor yang digunakan dalam penelitian ini belum tentu relevan bila diaplikasikan pada jenis smartphone lainnya, perlu adanya untuk mempertimbangkan mengubah objek penelitian seperti produk-produk gadget atau produk teknologi lainnya. Perbedaan dalam pemilihan target penelitian (populasi dan sampel) juga dapat memberikan hasil yang berbeda dari penelitian ini.

\section{Referensi}

Aaker, David A. 1997. Manajemen Ekuitas Merek: Memanfaatkan Nilai dari suatu Merek. Jakarta: Mitra Utama.

Aaker, David. 2011. Brand Relevance, Making Competence Irrelevant. Edisi pertama. United State America: The Jossey-Bass Business and Management Series.

Delgado-Ballester, E. 2004, Applicability of Brand Trust Scale accross Product Category. European Journal of Marketing, 38 (5), 573-592.

Dennis, Charles, Savvas Papagiannidis, Eleftherios Alamanos, Michael Bourkalis. 2015. The Role of Brand Attachment Strength in Higher Education. Journal of Business Research.

Ferdinand, Augusty Tae. 2006. Metode Penelitian Manajemen: Pedoman Penelitian untuk skripsi, Tesis dan Disertai Ilmu Manajemen. Semarang: Universitas Diponegoro.

Ghozali, Imam. 2013. Model Persamaan Struktural Konsep Aplikasi dengan Program AMOS 21.0. Edisi V. Semarang: Universitas Diponegoro.

Gronross C. 1990. Service management and marketing. Managing the moments of truth in service competition. San Francisco: Lexington Books. 
Kapferer, Jean Noel. 2008. The New Strategic Brand Management. Edisi ke 4. United Kingdom: Kogan Page.

Keller, Kevin Lane. 2013. Strategic Brand Management, Building Measuring, and Managing Brand Equity. Edisi keempat. British Library Cataloguing-in-Publication Data.

Kotler, Phillip, dan Kevin Lane Keller. 2009. Manajemen Pemasaran. Ed 13 Jilid 1. Jakarta: Erlangga.

Listani, Nining. 2013. Pengaruh Kepuasan Pada Merek Dan Komitmen Terhadap Niat Membeli Kembali (Studi Empirik Pada Konsumen Pulsa Elektrik All Operator). Jurnal Manajemen Dan Bisnis Vol.17 No. 1.

Louis, Didier dan Cindy Lombart. 2010. Impact of Brand Personality on Three Major Relational Consequences (Trust, Attachment, and Commitment yo The Brand). Journal Product and Brand Management.

Malar, Lucia, Harley Krohmer, Wayne D. Hoyer, and Bettina Nyffenegger. 2011. Emotional Brand Attachment and Brand Personality: The Relative Importance of the Actual and the Ideal Self. Journal of Marketing,75,35-52.

Mikulincer, Mario and Philip R. Shaver (2007), Attachment in Adulthood: Structure, Dynamics, and Change. New York:Guilford Press.

Moorman C, Zaltman G, Deshpande' R. Relationships Between Providers and Users of Marketing Research: The Dynamics of Trust within and between Organizations. J Mark Res 1992;29:314-29.

Morgan, Robert M. dan Shelby D. Hunt. 1994. The Commitment Trust Theory of Relationship Marketing. Journal of Marketing. Vol. 58. No. 3. 20 - 38.

Park, C. Whan, Deborah J MacInnis, Joseph Priester, Andreas B. Eisingerich, and Dawn Jacobucci. 2010. Brand Attachment and Brand Attitude Strength: Conceptual and Empirical Differentiation of Two Critical Brand Equity Drivers. Journal of Marketing Research, 74 (6), 1-17.

Rudolf Esch, Franz, Tobias Langner, Bernd H. Schmitt, Patrick Geus. 2006. Are brands forever? How brand knowledge and relationships affect current and future purchases, Journal of Product \& Brand Management, Vol. 15 Iss: 2, pp.98 - 105.

Wijaya, Indrawan. 2014. Pengaruh Ideal-Self terhadap Emotional Brand Attachment, melalui Product Involvement, Public Self-Conciousness, dan Self-Esteem Di Hotel Surabaya. Jurnal Manajemen Pemasaran.

Gounaris, Spiros P. 2005. Trust and Commitment Influences on Customer Retention: Insight from Business to Business Services. Journal of Business Research. 